\title{
Experiência com estudantes do ensino médio através da pesquisa escolar orientada
}

\section{Janaina Fialho}

\section{Professora adjunta do curso de biblioteconomia da Universidade Federal de Goiás}

Aborda a experiência com estudantes do ensino médio, através da pesquisa escolar orientada, com o objetivo de desenvolvimento do letramento informacional. Para a prática da pesquisa, foi escolhida uma turma do segundo ano do ensino médio do Centro de Ensino e Pesquisa Aplicada à Educação, em Goiânia, na disciplina de Biologia. Utilizou-se o Modelo ISP para orientar a pesquisa, em todas as suas fases. Conclui-se que o modelo é um referente interessante para trabalhar a pesquisa com os estudantes devido a sua flexibilidade, à consideração das emoções e ao estímulo à reflexão, no processo de pesquisa.

Palavras-chave: Pesquisa escolar orientada; Ensino médio-pesquisa; Modelo ISP; CEPAE.

\section{Experience with high school students through supervised school research}

This paper discusses an experience with high school students through supervised school research aiming to develop information literacy. In order to carry out this experience, we chose a high school second year biology class at Centro de Ensino e Pesquisa Aplicada à Educação (Center for Teaching and Research Applied to Education), in Goiania. We used the ISP model to guide all phases in the process. We concluded that the model is an interesting reference to work with students due to its flexibility, because it takes into consideration the students' emotions, and stimulates reflection in the research process.

Keywords: Supervised school research; High school research; ISP Model; CEPAE.

Recebido em 10. 10. 2012 Aceito em 08.02.2013 


\section{Introdução}

O presente relato concentra-se nas possibilidades de atuação do bibliotecário na atividade de pesquisa escolar, denominada doravante "pesquisa escolar orientada". Essa não é uma perspectiva nova, já de longa data sugere-se a vocação do bibliotecário escolar para a orientação da pesquisa e o incentivo à leitura. O termo "pesquisa escolar orientada" tem sido cunhado pela pesquisadora norte-americana Carol Kuhlthau (2007), que sugere que o bibliotecário e o professor acompanhem o estudante em todas as fases da pesquisa, do começo à apresentação final.

Em recente pesquisa de doutorado, ao investigar práticas educativas de bibliotecários em 28 bibliotecas da educação básica, em vários estados do país, Campello (2010) aponta que a orientação à pesquisa tem sido negligenciada pelos bibliotecários brasileiros, os quais têm se envolvido mais com o incentivo à leitura e se preocupado em atrair os estudantes para a biblioteca. A função educativa do bibliotecário sugere que ele é o profissional preparado para auxiliar os estudantes a localizar, selecionar, usar e avaliar a informação, dentro da perspectiva do letramento informacional.

É crescente o interesse dos estudantes do curso de graduação em Biblioteconomia da Universidade Federal de Goiás (UFG) por temáticas relacionadas à biblioteca escolar e à função educacional do bibliotecário. Tal interesse é consolidado através do desenvolvimento de trabalhos de conclusão de curso (TCC), estágios curriculares e supervisionados em bibliotecas de escolas públicas e particulares de Goiânia. O trabalho apresentado diz respeito ao uso da metodologia de Kuhlthau (2010) com estudantes do ensino médio do Centro de Ensino e Pesquisa Aplicada à Educação (CEPAE), na cidade de Goiânia, no estado de Goiás.

O CEPAE foi criado em 1966 e localiza-se na Universidade Federal de Goiás. A característica essencial de um colégio de aplicação é que ele está ligado a faculdades e universidades, diferenciando-se das demais escolas por funcionarem conforme as necessidades da instituição a que se vincula. Os professores da instituição são doutores, mestres e pesquisadores, envolvidos com o ensino do pré-escolar ao nível superior.

Tais profissionais apresentam propostas inovadoras de reforma escolar e destinam-se à educação dos estudantes e à formação de professores. Por essa razão e graças ao nível de competência de seu corpo docente, tais escolas oferecem um alto padrão de ensino, permitindo aos estagiários observar abordagens pedagógicas eficazes. Os princípios que norteiam a criação dessas escolas levaram-nas a serem conhecidas como escolas-laboratório, cuja missão é oferecer uma abordagem educacional inovadora, direcionada para o desenvolvimento de estudantes e professores.

O colégio de aplicação possui as seguintes funções: o desenvolvimento da educação básica e da pesquisa; a experimentação de novas práticas pedagógicas; a formação de professores; e a criação, implementação e avaliação de novos currículos e capacitação de docentes. Em relação à pesquisa, deve haver ambiente propício para uma variedade 
de pesquisas que possam ser realizadas por professores da educação básica, professores universitários e estagiários. As atividades de experimentação, estágio e extensão são privilegiadas no colégio, oferecendo ambiente para o desenvolvimento de projetos e propostas que proporcionem notáveis melhorias no processo de ensino-aprendizagem.

\section{Referencial teórico}

O Modelo ISP ou Processo de Busca de Informação (KUHLTHAU, 2004) caracteriza a atividade de pesquisa em estágios, conhecidos como Iniciação, Seleção, Exploração, Formulação, Coleção, Apresentação e Avaliação. Kuhlthau (2004) acompanhou estudantes no ensino médio e superior, realizando pesquisas em escolas americanas até chegar à construção do modelo. Segundo Kuhlthau (2004), o processo de busca de informação é interativo e cada estágio pode ser associado a estados cognitivos e afetivos. Constata-se, nessa perspectiva, que alguns estágios "são mais difíceis para os estudantes do que outros" (KUHLTHAU; MANIOTES; CASPARI, 2007, p. 17).

Kuhlthau (2004) desenvolveu o modelo sob a visão construtivista do aprendizado. O construtivismo apresenta 0 aprendizado como um processo dinâmico, em que todos os aspectos da experiência interagem. $O$ processo de construção é dinâmico e orientado por sentimentos, que interagem com pensamentos e ações. Nessa abordagem, o indivíduo é agente ativo do próprio conhecimento. Um ambiente construtivista de aprendizagem deve permitir que o sujeito crie sentido com informação contextualizada, o que Alves e Mendes (2000) denominam informação significativa. Uma informação só é significativa se "estiver vinculada às experiências do sujeito e se este possui alguns conhecimentos a priori em relação a essa" (ALVES; MENDES, 2000, p. 5) e incentiva as habilidades de avaliar e utilizar as informações, identificar problemas e apresentar soluções.

O estágio de Iniciação se dá quando o estudante reconhece que necessita de informação para completar a atividade de pesquisa. Nessa fase, ele normalmente expressa sentimentos de incerteza e apreensão. Ele reflete sobre a atividade para recordar sobre projetos anteriores em que tenha obtido informação e para identificar possíveis tópicos de pesquisa alternativos. As ações nessa fase comumente envolvem discussão de prováveis assuntos e abordagens.

Durante o segundo estágio, denominado Seleção, sentimentos de incerteza continuam a ocorrer; as atividades principais são identificar e selecionar um tópico geral de pesquisa. De acordo com Kuhlthau (2004), sentimentos de incerteza, muitas vezes, cedem ao otimismo, depois da escolha do tópico, e há uma prontidão para iniciar a busca por informação. Os pensamentos se centram em contrapor os tópicos prováveis de pesquisa a alguns critérios como interesse pessoal, informação disponível sobre aquele tópico, esforço e tempo que serão despendidos. 
O terceiro estágio, Exploração, é caracterizado por sentimentos de confusão, incerteza e dúvida, que frequentemente aumentam durante este período. Para muitos estudantes, esse é o estágio mais difícil do processo. A atividade principal é buscar informação sobre o tópico geral escolhido para ampliar a compreensão pessoal e estabelecer um foco sobre o mesmo. Os pensamentos se centram no fato de o estudante tornar-se orientado e suficientemente informado sobre o tópico, com o objetivo de estabelecer um foco para a pesquisa ou um ponto de vista pessoal. A informação encontrada comumente entra em conflito com construtos prévios, e essa, proveniente de diversas fontes, muitas vezes parece inconsistente e incompatível. As ações dizem respeito à localização de informação sobre a questão escolhida, prática de leitura para se tornar informado e relacionamento da nova informação ao que já é conhecido (KUHLTHAU, 2004).

Formulação, o quarto estágio do modelo ISP, é, para muitos estudantes, o momento decisivo do processo, em que o sentimento de incerteza diminui e há um aumento de confiança. A atividade principal é formar um foco, a partir da informação encontrada, através de leitura e reflexão sobre o tópico ou problema. Os pensamentos envolvem identificar e selecionar ideias para formar uma perspectiva focada sobre o tópico. As estratégias estão em torno de leitura e reflexão, conversa e escrita sobre temas e ideias. Caso o processo de construção ocorra, o tópico torna-se mais personalizado. Nesse período, uma mudança nos sentimentos é comumente experimentada, sinalizando o aumento do sentimento de confiança e de clareza sobre o tópico. Uma clareza de foco para o tópico de pesquisa capacita o estudante a se mover para o próximo estágio de busca, direcionando-o para a coleta de informação (KUHLTHAU, 2004).

Coleção é o quinto estágio do processo, quando ocorre uma interação mais efetiva e eficaz entre o estudante e o sistema de informação. Nesse ponto, a atividade é reunir informação sobre o tópico focado. Os pensamentos se centram em buscar uma forma de definir e dar suporte ao foco. As ações de pesquisa envolvem selecionar informação pertinente e fazer anotações detalhadas do que esteja relacionado especificamente ao foco, já que, depois do estágio de Formulação, informações generalizadas já não têm mais relevância. O estudante, com um senso claro de direção, pode especificar sua necessidade de informação relevante e direcionada, facilitando uma busca abrangente dos recursos disponíveis. Sentimentos de confiança continuam a aumentar, à medida que o de incerteza diminui, com interesse mais profundo pelo projeto (KUHLTHAU, 2004).

O modelo original de Kuhlthau (2004), realizado com estudantes do ensino médio, propunha os estágios de Exploração, Formulação e Coleção como distintos e separados (KUHLTHAU, 2004). No entanto, a confirmação longitudinal do modelo com os mesmos estudantes, na conclusão do ensino superior, identificou que esses três estágios são sobrepostos e se fundem. Os participantes descreveram um processo mais espiral, em que os pensamentos emergentes iam mudando e se desenvolvendo, ao invés de um ponto distinto de formulação. Essa 
constatação indicou mudanças significativas relativas às percepções dos estudantes sobre o processo de busca de informação, principalmente em três quesitos: nas atividades da pesquisa, no estabelecimento de um foco/direção para a mesma e, também, na coleta de informações (KUHLTHAU, 2004).

Indicou, também, que, à medida que eles se tornam mais experientes e maduros intelectualmente, o que inclui mais experiência no uso da biblioteca e das fontes de informação, suas percepções sobre o processo de busca de informação sofrem alterações importantes, embora os estágios do processo continuem os mesmos (KUHLTHAU, 2004). Há um aspecto crítico nessa questão, porque, normalmente, os estudantes são inclinados a irem diretamente para a fase de coleta de informações (Coleção) assim que selecionam o tópico de pesquisa (Seleção). Todavia, o mais importante a se fazer nesse momento, segundo Kuhlthau (2004), é ler e refletir sobre o tópico, listar fatos importantes e ideias interessantes, com o objetivo de estabelecer um foco para a pesquisa. Nos estágios iniciais da pesquisa, os estudantes não compreendem claramente a tarefa de estabelecer um foco a partir da informação encontrada. Eles precisam de orientação para que avancem para as fases posteriores (KUHLTHAU, 2004).

No estágio de Apresentação, sentimentos de alívio são comuns. Há um sentimento de satisfação se a atividade de pesquisa foi bem sucedida, ou de desapontamento, caso contrário. A principal atividade é completar a busca e se preparar para apresentar os resultados. Estratégias de organização da informação, como resumos, constituem técnicas importantes nessa fase. À medida que os estudantes estão mais maduros intelectualmente, seus sensos de propriedade sobre os produtos de pesquisa aumentam, buscando construir uma expertise sobre o assunto (KUHLTHAU, 2004).

A Avaliação ocorre no momento de reflexão depois da conclusão do processo de pesquisa. Há certa indagação se esse seria um estágio separado ou integrante do sexto estágio. Kuhlthau (2004) apresenta alguns aspectos da avaliação incorporados ao sexto estágio de Apresentação. Estudantes consideraram essa atitude como uma oportunidade de desenvolver um senso de competência sobre o processo de busca, o que os auxiliou, também, a percebê-lo como um processo composto de fases distintas. É um momento de reflexão sobre toda a atividade e o conteúdo da aprendizagem, incluindo os pontos fortes e fracos do processo de pesquisa, fundamental para que eles possam refletir sobre suas dificuldades, procurando se aperfeiçoar para trabalhos futuros.

\section{Metodologia}

\subsection{Caracterização do projeto}

A biblioteca do CEPAE, criada em 1968, faz parte do Sistema de Bibliotecas da UFG, funciona de segunda a sexta e atende a comunidade do colégio, estudantes da universidade e da comunidade vizinha à 
universidade. Por esse motivo, a comunidade escolar tem acesso a todas as bibliotecas do sistema. Possui três funcionários fixos, sendo um bibliotecário e dois professores, assim como bolsistas e estagiários de Biblioteconomia. O acervo é composto de aproximadamente 20600 exemplares nos assuntos de literatura infantil e juvenil (em português e inglês), livros didáticos da educação básica, revistas, jornais, teses, dissertações e monografias realizadas por professores da instituição. Oferece os seguintes serviços e produtos: empréstimo domiciliar, pesquisa escolar, atividades culturais, exposição de livros e hora do conto. A contação de estórias acontece semanalmente com os estudantes do ensino fundamental e há um trabalho integrado do bibliotecário com os professores para o incentivo à leitura.

O projeto foi desenvolvido para a disciplina "Estágio Supervisionado $\mathrm{B}^{\prime \prime}$, do curso de Biblioteconomia da UFG, com os seguintes objetivos (geral e específicos): trabalhar a pesquisa escolar orientada com a turma de estudantes do ensino médio; desenvolver as atividades de busca e uso de informações na prática da pesquisa escolar orientada; ajudar no desenvolvimento do letramento informacional dos estudantes; e orientar a busca e o conceito de fontes de informação, nos suportes tradicionais e digitais e orientar os estudantes no processo de normalização da pesquisa.

O trabalho foi proposto pelo estagiário através de orientação da bibliotecária do colégio, integrando a bibliotecária, o estagiário e a professora ${ }^{1}$ da disciplina de Biologia no planejamento, execução e avaliação das atividades de pesquisa escolar orientada. A amostra de pesquisa foi composta por estudantes do $2^{\circ}$. ano do ensino médio da disciplina de Biologia do CEPAE, na cidade de Goiânia. A escolha da disciplina se deu devido à disponibilidade da professora, sua abertura para o trabalho conjunto e a compatibilidade com os horários do estagiário. A pesquisa escolar orientada foi realizada durante o mês de outubro de 2010, sendo o mês de setembro utilizado para o planejamento das atividades e o mês de novembro para análise dos resultados e redação do relatório final de estágio.

Foi solicitado à professora da disciplina que escolhesse uma de suas turmas para a atividade. Após análise da professora e do estagiário, escolheu-se trabalhar com a turma do segundo ano do ensino médio, por considerarem que os estudantes já estão mais experientes em relação à prática de pesquisa. Os estudantes do terceiro ano foram excluídos, devido ao fato de estarem com as atividades mais centradas no vestibular. A partir de então, foi conversado com a professora para que ela apontasse o que seria importante para ser trabalhado com os estudantes, no processo de pesquisa escolar. Escolheu-se o tema geral de pesquisa "mamíferos", sendo que os estudantes, ao se organizarem em grupos, tiveram autonomia para escolher o tema específico, dentro do assunto geral determinado.

${ }^{1}$ Licenciada em Ciências Biológicas e mestre em Biologia pela UFG. 


\subsection{Atividades desenvolvidas}

Como as aulas da disciplina de Biologia eram ministradas as quintas feiras, em dois horários, foi elaborado juntamente com a professora um cronograma de atividades a serem desenvolvidas no mês de outubro de 2010. Utilizou-se, nesses dias, o diário de campo para registro das informações. As fases do Modelo ISP (KUHLTHAU, 2010) foram trabalhadas durante os encontros, conforme o quadro seguinte:

Quadro 1 - Cronograma de Atividades

\begin{tabular}{l|ll}
\hline Data & Atividade Principal \\
\hline $07 / 10$ & Pesquisa na biblioteca \\
\hline $14 / 10$ & Pesquisa na sala de informática & \\
\hline $21 / 10$ & Parte escrita do trabalho & \\
\hline $28 / 10$ & $\begin{array}{l}\text { Entrega do trabalho escrito com breve } \\
\text { apresentação }\end{array}$ \\
\hline
\end{tabular}

Fonte: Dados da pesquisa.

No início do trabalho, a professora apresentou o estagiário e explicou a atividade que seria desenvolvida. Assim, no primeiro momento, foram apresentados conceitos de pesquisa, como deve ser feita, seus passos e o que deve ser considerado para realizá-la. Os estudantes ficaram empolgados e com expectativa de novidade em relação à experiência. Alguns fizeram perguntas em relação ao que foi apresentado. Essa pode ser caracterizada como a fase de Iniciação do Modelo ISP (KUHLTHAU, 2010).

$\mathrm{Na}$ fase de seleção do assunto (Seleção), foi orientado sobre a importância da reflexão sobre o assunto para a realização da pesquisa. No caso deste trabalho, o assunto foi determinado pela professora de Biologia com o tema geral, sobre o qual os estudantes deveriam buscar fontes de informação. Foi entregue pela professora uma sugestão de esquema básico para a pesquisa, contendo os seguintes itens: tema para pesquisa - mamíferos; características gerais; destacar a que lhes é exclusiva; subclasse dos mamíferos - características e exemplos; reprodução, respiração e excreção; maior mamífero; curiosidades.

$\mathrm{Na}$ fase de exploração das informações (Exploração), buscou-se a orientação quanto à estrutura hierárquica dos assuntos, do geral para o particular, a utilização de termos de busca e a realização de uma busca exploratória sobre o assunto. Foi explicado aos grupos que, dentro da Biologia, existem vários assuntos mais específicos, que vão se subdividindo até um mais particular, como, por exemplo: reino animal mamíferos - cetáceos - baleias. Os estudantes foram orientados sobre a forma de organização da biblioteca e a diferença entre os materiais, como livros, obras de referência, ficção, não ficção, biografias, revistas e jornais. Foram direcionados, nessa fase, a fazerem anotações das informações interessantes e relevantes para a pesquisa, bem como as fontes das quais foram retiradas. 
Na sala de informática, foi ensinado como a informação está organizada na internet, e os conceitos de Web, site, rede de relacionamentos, hipertexto e hipermídia e, também, a forma que pode ser recuperada, através dos diretórios e mecanismos de busca. Foi ressaltado, também, que, ao realizarem buscas na internet, critérios de pertinência, relevância e confiabilidade devem ser considerados e que muitas informações na Web não são confiáveis e, por isso, não devem ser utilizadas na pesquisa. Assim, puderam realizar um levantamento das informações sobre os assuntos que buscavam e não ficar apenas com um livro ou a primeira página da internet que aparecesse. Foi solicitado para que anotassem as informações relevantes para a pesquisa, sempre com as referências. Alguns estudantes demonstraram sentimentos de entusiasmo, ao afirmarem: "agora será mais fácil para eu conseguir uma bolsa na faculdade" (Estudante 1); "é bom para o currículo da gente" (Estudante 2).

Nesse momento, os estudantes acharam que seria um trabalho como os outros, pegando e copiando qualquer livro, mas, depois, perceberam que o processo seria mais trabalhoso. Com a explicação sobre as fontes de informação, eles pensaram que teriam que ler mais para escolher o foco da pesquisa. Alguns observaram que livros antigos trazem informações desatualizadas. Aprenderam, também, sobre a necessidade de ler mais, a partir da compreensão que tiveram do que foi lido. Eles preferiram a internet a livros impressos, devido aos recursos de hipertexto e hipermídia.

Assim que chegaram à biblioteca, já foram buscar os livros nas estantes. Alguns, principalmente os meninos, escolheram os livros pela capa. Os critérios que utilizaram para escolher os livros foram: se é didático ou não, se tem a capa colorida e imagens. Os livros mais velhos com a capa da mesma cor foram considerados feios. Eles não gostaram muito de enciclopédias, devido à padronização da capa. Usaram muitos dicionários, principalmente na internet. Para a pesquisa, eles se sentiram desorientados para localizar o assunto.

O acompanhamento da busca na internet demonstrou que os estudantes iam a qualquer site, sem utilizar critérios de avaliação da informação e se entendiam alguma coisa do primeiro site que aparecia ou gostassem de alguma imagem bonita ou chamativa, os utilizavam para a pesquisa. Sendo assim, foi-lhes orientado sobre os critérios de avaliação de fontes de informação na internet, utilizando como referência a obra de Tomaél et al. (2001). Não gostaram de conhecer os diretórios e outros mecanismos de busca como o Altavista, sendo que um estudante afirmou "não vejo necessidade de pesquisar nesse diretório, basta ir direto ao Google" (Estudante 3). Isso demonstrou que costumavam utilizar apenas um mecanismo de busca e de uma única forma para acessar informação na Internet. Também, demonstraram desconhecimento de estratégias de busca avançadas na Internet.

$\mathrm{Na}$ fase de definição do foco (Formulação), foi ensinado a cada grupo que todo trabalho deve ter um tema específico dentro de um assunto geral - o foco da pesquisa, que deveriam manter ao longo do 
processo. Dentro do assunto geral mamíferos, cada grupo deveria escolher um tema específico para realizar o trabalho, sendo a escolha livre. Alguns estudantes não compreenderam a diferença do tema geral para o específico. Um grupo escolheu um tema mais geral devido ao vestibular, porque pensaram que estudariam mais sobre o tema. Outro quis algo mais rápido e objetivo. De maneira geral, os estudantes selecionaram um foco específico a partir do que leram e acharam mais interessante, sendo que a maioria escolheu um foco mais abrangente. Houve maior curiosidade em conhecer a diferença entre a ordem dos mamíferos e houve apenas um trabalho sobre o tópico curiosidades.

$\mathrm{Na}$ fase coleta de informações (Coleção), foi orientado aos estudantes que reunissem informações que definissem, ampliassem e apoiassem o foco da pesquisa. Foi dito que com o tema específico - o foco, deveriam agora buscar informações a respeito dele e que poderiam adaptá-lo e alterá-lo, à medida que reunissem informações sobre ele. Foi solicitado que fossem às páginas da National Geographic, Scientific American, Galileu e Super Interessante, para buscarem informações atualizadas ou interessantes sobre o foco de cada grupo. Nessa fase, os estudantes recorreram à professora para pedirem ajuda na pesquisa. Com o foco já definido, eles voltaram a pesquisar sobre o assunto específico em páginas na Internet, em livros da biblioteca e alguns em enciclopédias. Tiveram dificuldade em recuperar informação nas revistas eletrônicas indicadas.

$\mathrm{Na}$ fase de preparação do trabalho escrito (Apresentação), foi orientado aos estudantes que organizassem o trabalho escrito de acordo com as normas da ABNT, e foi-lhes ensinado sobre as normas para trabalhos acadêmicos, referências e citações. Para escreverem, foi dito para ficarem atentos à coesão e coerência do texto, conectando as partes e os parágrafos, a partir do que haviam anotado, e colocando as referências das fontes consultadas no final. Aprenderam a elaborar corretamente a referência de sites na pesquisa, pois, anteriormente, só colocavam o link dos mesmos. Estruturaram corretamente o trabalho de pesquisa, com capa, sumário, introdução, desenvolvimento, conclusão e referências, conforme Ihes foi orientado. Também, foi ensinada a diferença entre citação, paráfrase e resumo.

Para a redação do trabalho, eles leram e tentaram fazer conexão das ideias, unindo os parágrafos através da ordenação das mesmas. No momento de escrever os textos, buscaram dar coerência a eles. Selecionaram os textos a partir do rascunho de anotações que fizeram desde o começo, o que consideraram muito importante para trabalharem a parte escrita. Foi observado que os grupos se ajudaram, mostrando um trabalho para o outro e repassando as informações. Alguns estudantes afirmaram: "a ABNT é uma empresa que ensina como fazer um trabalho científico" (Estudante 4); "a gente só entregava um pedaço do trabalho e não sabia" (Estudante 5); "a questão da formatação de trabalhos já nos havia sido apresentada pelo professor de Geografia e os componentes deste grupo já têm o domínio sobre as técnicas, mas, ao passar as convenções da ABNT para os demais colegas, novamente lhes propiciou 
uma oportunidade de aprender algo que será tão importante na carreira acadêmica" (Estudante 6). O trabalho foi entregue escrito e com apresentação oral em sala de aula.

$\mathrm{Na}$ fase da avaliação do processo (Avaliação), os estudantes comentaram e refletiram sobre a experiência. Também, fizeram perguntas para a professora para esclarecerem dúvidas sobre o assunto abordado. Dentre as diferenças percebidas com a pesquisa escolar orientada, pôdese perceber maior exigência da professora com as referências usadas na pesquisa. No geral, a turma aprendeu o que foi ensinado. Nesse caso, passaram a ter noções mais claras das regras de organização e normalização da pesquisa.

A professora considerou a experiência excelente e ressaltou a importância da pesquisa escolar. Nunca houve esse trabalho no colégio, já que os funcionários da biblioteca sempre estiveram mais envolvidos com atividades de empréstimo e hora do conto. Os estudantes gostaram e consideraram que fizeram um trabalho completo, como uma monografia, um trabalho mais "suado", com mais energia. Os mesmos consideraram de grande importância o trabalho desenvolvido pelo estagiário em parceria com o bibliotecário e a professora, pois reconheceram que aprenderam a lidar melhor com as diversas fontes de informação, conhecendo-as e explorando o potencial que elas possuem; bem como vislumbraram a experiência como um amadurecimento para a vida acadêmica.

\section{Conclusões}

Pela análise feita, pode-se afirmar que o Modelo ISP (KUHLTHAU, 2010) é um referente interessante para a compreensão do comportamento informacional de estudantes da educação básica, na prática da pesquisa. Duas possibilidades importantes do modelo são a consideração das emoções e o estímulo à reflexão. A compreensão da atividade de pesquisa, como processo e não apenas como elaboração de um produto final, é um aspecto de grande potencial que precisa ser trabalhado com os estudantes; de fato, é necessário "ensiná-los" a pesquisar. Na escola, tal ensino é bastante proveitoso se feito de forma compartilhada entre o professor e o bibliotecário e essa é uma tese compartilhada pelos estudiosos do assunto. No entanto, a escola que não possui biblioteca e bibliotecário pode, também, utilizar as fases do modelo para o ensino da pesquisa, adaptando-o a sua realidade.

Conforme colocado anteriormente, o Modelo ISP se torna relevante à medida que conduz a uma compreensão da pesquisa enquanto processo e não apenas como elaboração de um produto final. Isso é potencialmente útil na era da Internet, na qual os estudantes têm mais facilidade e um mundo de possibilidades que os leva, muitas vezes, à ausência de reflexão e, consequentemente, ao imediatismo das respostas. Portanto, podem ser considerados como aspectos relevantes do modelo: a) a consideração dos sentimentos no processo de pesquisa; b) o estabelecimento do foco, como um caminho a ser percorrido, um alvo para a pesquisa; e c) a 
flexibilidade, ou seja, o fato de poder ser adaptado por escolas em diferentes circunstâncias e estruturas.

Em relação à pesquisa escolar, é importante ressaltar alguns fatores influentes, tais como: o tempo disponível para realizar a pesquisa; a importância da atividade de reflexão e do estabelecimento do foco; as especificidades das disciplinas do conhecimento e o papel relevante das emoções e da orientação; e do começo ao fim da prática investigativa. O tempo é um fator altamente significativo na pesquisa e deve ser considerado em todo o processo; refletir é essencial, devendo levar-se em conta o conhecimento prévio sobre o assunto, as experiências anteriores de pesquisa e o estabelecimento de conexão entre as ideias; as especificidades das disciplinas também devem ser consideradas, pois elas influenciam na forma de buscar informação, nas fontes utilizadas, na metodologia e na apresentação final da pesquisa.

\section{Referências}

ALVES, M. B. M.; MENDES, E. B. Um modelo de aprendizagem construtivista para busca de informação significativa em bibliotecas virtuais. In: SEMINÁRIO NACIONAL DE BIBLIOTECAS UNIVERSITÁRIAS, 11., 2000, Florianópolis. Anais... Florianópolis: UFSC, 2000. Disponível em: <http://snbu.bvs.br/snbu2000/docs/pt/doc/t143.doc >. Acesso em: 1 jul. 2011.

CAMPELLO, B. S. Perspectivas de letramento informacional no Brasil. Encontros Bibli: Revista Eletrônica de Biblioteconomia e Ciência da Informação, Florianópolis, n. 15, v. 29, p. 184-208, 2010. Disponível em: $<$ http://www.periodicos.ufsc.br/index.php/eb/article/view/10470/12426>. Acesso em: 1 jul. 2011

KUHLTHAU, C. C. Seeking meaning: a process approach to library and information services. 2. ed. Norwood: Ablex Publishing Corporation, 2004. $247 \mathrm{p}$.

KUHLTHAU, C. C. Como orientar a pesquisa escolar: estratégias para o processo de aprendizagem. Belo Horizonte: Autêntica, 2010. 252 p.

KUHLTHAU, C. C.; MANIOTES, L. K.; CASPARI, A. K. Guided Inquiry: learning in the $21^{\text {st }}$ Century. Westport: Libraries Unlimited, 2007. $170 \mathrm{p}$.

TOMAÉL, M. I. et al. Avaliação de fontes de informação na Internet: critérios de qualidade. Informação \& Sociedade: Estudos, João Pessoa, v. 11 , n. 2, p. 1-14, 2001. 